Ana Skledar

Zagreb

\title{
CUATRO POETAS VANGUARDISTAS Y LA CONTEMPORANEIDAD DE SUS POÉTICAS: HUIDOBRO, VALLEJO, GIRONDO Y BORGES
}

I.

El surgimiento de los vanguardismos artísticos y literarios está relacionado con el período de mayor intensidad social, ideológica e histórica del siglo XX: el período que va desde la Primera Guerra Mundial del 14 al inicio de la Segunda en 1939. El término vanguardias surge en Francia durante los años de la Primera Guerra. Su origen está en la palabra francesa avant-garde, término de origen militar y político, que refleja el espíritu de lucha, de combate y de confrontación que el nuevo arte oponía frente al arte académico del siglo XIX.

El arte vanguardista significa un espíritu nuevo, una ruptura, una suvbersión absoluta, una rebeldía contra lo antiguo, lo naturalista y la cultura burguesa. Surge una estética nueva que se opone al retoricismo del la estética simbolista y modernista. La escritura se aleja de la mímesis, aparece el verso libre como reflejo de la liberación rítmica, se crean nuevas imágenes y un nuevo lenguaje (moderno), se deshacen las formas convencionales ... Las manifestaciones artísticas son extraordinarias, con una versatilidad y agilidad desconocidas hasta entonces. Los llamados ismos sucederán uno tras otro - dadaísmo, expresionismo, impresionismo, futurismo, surrealismo ...

Aunque el foco de la vanguardia se encontraba en Europa, los poetas americanos seguían la misma linea del pensamiento. Toda la conmoción que está pasando en Europa se siente también en la América Latina - donde al mismo tiempo aparecen dos ismos propios: creacionismo y ultraísmo. Sin embargo, no se trata sólo de seguir y desarrollar las influencias de la vanguardia europea, sino también de una reacción propia americana.

Al principio del siglo XX todo el mundo obtuvo un gran impulso en la forma por el rápido progreso técnico. Nuevos medios de transporte, nuevas velocidades hace poco impensados, nuevos medios de comunicación, cambios drásticos de la vida cotidiana ... La gente se halla atrapada en ciudades grandes, rodeada de novedades técnicas y de una euforia por el progreso. Además, en Europa, la Primera Guerra, una guerra "moderna", causa conmoción e inseguridad; todo el continente se halla en una vorágine.

Por todo esto, el hombre urbano, a pesar de su entusiasmo por el progreso técnico y el mejoramiento de la vida, a pesar de la sorpresa y de la fascinación por las novedades, empieza a experimentar otra cara de este rápido proceso de modernización. La modernización inevitablemente trae consigo la alienación de la gente, el alejamiento de la naturaleza y de otras personas. El hombre se halla sorprendido y perdido, inseguro y no preparado para el futuro que ya está empezando.

Los poetas, seres extremadamente sensibles, reaccionan. Utilizan el vocabulario técnico, moderno, describen paisajes urbanos, hechos de edificios, faroles, tranvías, automóviles, alambres y aviones. El sentido de la vida es vago, si no completamente perdido, las 
certidumbres sociales se deshacen (después de la guerra los grandes países europeos se reorganizan, los sistemas sociales se transforman y la nueva clase media juega un papel más importante, la religión pierde su influencia sobre la vida política ...). Por eso el significado de las palabras desaparece, incluso las palabras se deshacen. Los poetas tratan de comunicar sus emociones complicadas, sus miedos, sus ansias, sus dolores. Pero el sistema lingüístico ya no representa medio de expresión adecuado sino medio de limitación. Los poetas buscan otras maneras de expresar su emoción interior. Por eso, el poema se convierte en un grito, en sonidos desarticulados.

Se trata de la búsqueda de una manera apropiada de filtrar el mundo que se ha vuelto 'demasiado', una manera de aliviarse. Las expresiones vanguardiastas son nuevas, inesperadas, chocantes, oximorónicas, absurdas. Pero lo que es fascinante es que todavía siguen así, a pesar del tiempo que ha pasado. En el nuevo siglo XXI algunos poemas vanguardistas todavía suenan inexplicables, nuevos $\mathrm{y}$, sin embargo, expresan las mismas emociones.

Después del primer choque de la modernización el mundo se acostumbró, la gente aceptó y aprendió a usar todos los beneficios de la era moderna. Vinieron nuevas guerras, vinieron y pasaron nuevas modas ... En los años 60 y 70 ocurrió un nuevo impulso, otra vez, la vida se hizo de repente mucho mas rápida, y empezó la época de los medios de comunicación. Ahora estamos experimentando la última revolución - la informática. La vida se hizo aún más rápida, la comunicación es casi instantánea por medio del Internet. $\mathrm{Y}$ de nuevo la gente está aislada en urbes enormes, sola entre las multitudes humanas, alejada de los valores humanos, perdida. Por eso, los poemas de los vanguardistas funcionan ahora también. No nos fascinan más los automóviles y aviones, sino la globalización, el internet, la realidad virtual ... Cambian circunstancias sociales cada día, la mayoría ya no tiene fe en nada, la naturaleza se está muriendo ... Por eso los versos como, por ejemplo, "Estás perdido Altazor" (Huidobro, 1998: 61, v. 9) suenan tan verdaderos. El hombre de hoy se puede encontrar en los versos de entonces. Y si no existe el remedio para el trágico estado de la vida humana, tal vez podamos encontrar consuelo.

\section{II.}

En 1914 Chaplin crea el personaje Carlitos; en 1915 Einstein transforma la concepción mecanicista del mundo con La teoría de la relatividad generalizada; en 1916 Freud abre el mundo del inconsciente con su Introducción al psicoanálisis. Mientras tanto, en 1914 Vicente Huidobro escribe su manifiesto de los principios de la Poética de la nueva poesía en Prefacio a Adán; en 1919 publica Altazor, obra cumbre del creacionismo e influencia fundamental en todos los movimientos de vanguardia de España y América Latina; en 1922 Oliverio Girondo publica la innovadora poesía de Veinte poemas para ser leídos en el tranvía, César Vallejo publica su revolucionario Trilce; en 1923, resultado de sus contactos con el expresionismo alemán y el ultraísmo español, Jorge Luis Borges publica Fervor de Buenos Aires, en 1924 Oliverio Girondo escribe el manifiesto vanguardista de la revista Martín Fierro.

Aunque los cuatro poetas (Huidobro, Vallejo, Girondo y Borges) pertenecen a la vanguardia y en la poesía de cada uno hay notables características de la estética vanguardista, existen diferencias significativas entre ellas. 
A Huidobro y a Borges los podemos considerar como dos polos opuestos de la poética vanguardista.

Huidobro lleva la desintegración del lenguaje, de la gramática y de la forma al extremo. El creacionismo se basa en el postulado que la poesía no debe ser mímesis (es decir, imitación de la naturaleza), sino creación pura. En 1916 publica su Arte poética, el programa ideológico del poeta creacionista, donde dice:

\author{
Por qué cantáis la rosa, joh Poetas! \\ Hacedla florecer en el poema; \\ sólo para nosotros \\ viven todas las cosas bajo el Sol.
}

El poeta es un pequeño Dios. (Huidobro, 1916. En: Jiménez 2000: 139)

La palabra está liberada de su instrumentalidad como medio de comunicación. El poeta "inventa" combinando nuevas palabras. Este proceso se puede observar en Altazor, que empieza casi como poesía 'regular' y termina con una secuencia de sonidos, de vocales que representan un grito y la desarticulación completa - no sólo del lenguaje y de la poesía, sino también del mundo. No es una obra 'acabada' en el sentido tradicional. Es una obra en progresión, una 'obra abierta'.

El prefacio está en prosa y en él se explica cómo empieza la caída en paracaídas. El primer canto es un todo completo; los cantos desde el tres al siete hay que considerarlos aparte y en conjunto, mientras el segundo es caso aparte.

El primer canto es el más largo (700 versos) y de arquitectura más sólida. Comienza con una serie de preguntas especulativas que Altazor se plantea a sí mismo ("Altazor, ¿por qué perdiste tu primera serenidad?"). Se nota un sentimiento de soledad, casi una amenaza ("Estás perdido Altazor / Solo en medio del universo") pero luego nos damos cuenta de que Altazor está hablando consigo mismo ("Soy yo Altazor / Altazor / Encerrado en la jaula de su destino"). La vida está percibida como caída temporal y espacial hacia el olvido. (Costa, René de: "Introducción". En Huidobro, 1998: 11- 51):

\author{
Cae en infancia \\ Cae en vejez \\ Cae en lágrimas \\ Cae en risas \\ Cae en música sobre el universo \\ Cae de tu cabeza a tus pies \\ Cae de tus pies a tu cabeza \\ Cae del mar a la fuente \\ Cae al último abismo de silencio \\ Como el barco que se hunde apagando sus luces \\ (Huidobro, 1998: 63, vv. 47-56)
}


Aunque a veces es muy pesimista, especialmente cuando se trata de la pérdida de la fe, personal y global:

Abrí los ojos en el siglo

En que moría el cristianismo

Retorcido en su cruz agonizante

Ya va a dar el último suspiro

Y manana qué pondremos en el sitio vacío?

(Huidobro, 1998: 64, vv. 91-95)

Soy el ángel salvaje que cayó una mañana

En vuestras plantaciones de preceptos

Poeta

Anti poeta

Culto

Anti culto (Huidobro, 1998: 73, vv. 367-372)

existe fe en el poder redentor de la poesía:

Quiero darte una música de espíritu

Música mía de esta cítara plantada en mi cuerpo

Música que hace pensar en el crecimiento de los árboles

(Huidobro, 1998: 81, vv. 605-607)

Termina con un cierre calmante:

No hay peligro en la noche pequeña encrucijada

$\mathrm{Ni}$ enigma sobre el alma (Huidobro, 1998: 83, vv. 670-671)

\section{Silencio}

Se oye el pulso del mundo como nunca pálido

la tierra acaba de alumbrar un árbol (Huidobro, 1998: 83, vv. 682-684)

Como se puede ver, en el primer canto el lenguaje todavía funciona bien, y se trata de la poesía "normal", en verso libre con imágenes un poco distorsionadas. Pero, aunque se puede leer como poesía "normal" se trata de una nueva poesía a la cual el lector de aquel entonces no estaba acostumbrado.

El segundo canto es una oda a la mujer ("Mujer el mundo está amueblado por tus ojos"), que tiene poco o nada que ver con el primer canto. No funciona como progresión lógica del canto primero. el punto común es la busca de un nuevo sistema expresivo.

El tercer canto cuestiona la eficacia del instrumento poético ("Manicura de la lengua es el poeta"). La posibilidad lingüística es puesta en uso y abuso:

\footnotetext{
" "normal" quiere decir la poesía a la cual el público de aquel entonces estaba acostumbrado - poemas organizados en estrofas simétricas, con rima ...
} 
Poesía aún y poesía poesía

Poética poesía poesía

Poesía poética del poético poeta

poesía

Demasiada poesía (Huidobro, 1998: 95, vv. 51-55)

Se nota una dirección clara hacia la progresiva desarticulación que culmina en el grito del canto siete.

El cuarto canto es diferente de los cantos anteriores. "No hay tiempo que perder" es su leitmotiv. Se trata de una rica gama de posibilidades expresivas, desde el fluir psíquico del surrealismo ("Para hablar de la clausura de la tierra y la llegada del día agricultor a la nada amante de lotería sin proceso ni niño para enfermedad pues el dolor imprevisto ...") hasta una especie de de-construcción - deconstruye palabras en sus componentes para obtener palabras nuevas y nuevos significados ("Aquí yace Rosario río de rosas ...", "Aquí yace Raimundo raíces del mundo ..."), distorsiona palabras para obtener palabras completamente nuevas ("El meteoro insolente cruza por el cielo / El meteplata el metecobre / El metepiedras en el infinito") con nuevas posibilidades expresivas:

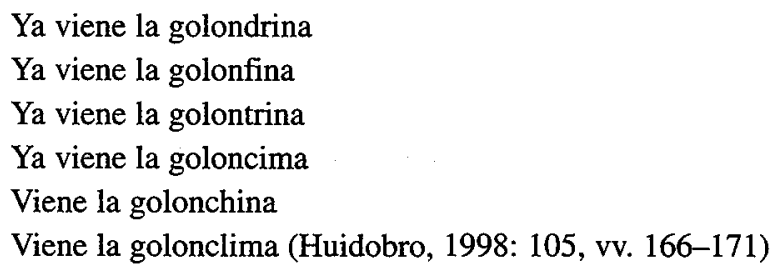

Al final ya hay trazos de desintegración total, pero todavía no se trata de un grito sino de un canto:

El pájaro tralalí canta en las ramas de mi cerebro

Porque encontró la clave del eterfinifrete

Rotundo como el unipacio y el espaverso

Uiu uiui

Tralalí tralalá

Aia ai ai aaia i i (Huidobro, 1998: 110, vv. 334-339)

En el quinto canto "comienza el campo inexplorado" (Huidobro, 1998: 111, v. 1) Aunque haya fragmentos de poesía "normal" (o sea, casi convencional en cuanto a la forma), se trata del inicio de una anarquía lingüística, las reglas se ignoran, todo es variable - las palabras son transformadas, los sustantivos se hacen verbos y al revés ...:

La cascada que cabellera sobre la noche

Mientras la noche se cama a descansar

Con su luna que almohada al cielo (Huidobro, 1998: 125, vv. 497-499) 
El sistema de 'de-escritura' va defamiliarizando lo familiar:

Sal rosa rorosalía

Sal rosa al día

salía al sol rosa sario

Fueguisa mía sonrodería rososoro oro (Huidobro, 1998: 126, vv. 517-520)

La poesía se convierte en un juego de palabras y recuerda a los cantos de niños, cuyo significado se está perdiendo.

En el canto sexto el léxico es todavía reconocible (se perciben patrones rítmicos de la poesía tradicional), pero el significado no. Se crea la ilusión de la poesía - algo que suena como poesía. Este canto no se lee sino que se pronuncia:
Alhaja apoteosis y molusco
Anudado
noche
nudo
El corazón
Esa entonces dirección

nudo temblando (Huidobro, 1998: 131, vv. 1-7)

El séptimo canto está escrito en un lenguaje inventado. Lo único reconocible es el sistema fónico del castellano:

\author{
Lusponsedo soilinario \\ Aururaro ulisamento lalilá \\ Ylarca murllonía \\ Hormajauma marijauda \\ Mitradente \\ Mitrapausa \\ Mitralonga \\ Mistrasola (Huidobro, 1998: 137, vv. 17-25)
}

Termina en un grito:

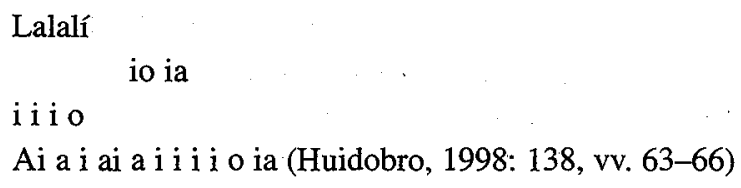

El proceso de desintegración es también notable en la organización formal de su poesía. Altazor está dividido en cantos, pero hacia el final del poema se pierde la simetría de los cantos también. 
Borges, por otra parte, es ultraísta y quiere ir 'más allá' de la estilística modernista. Los procedimientos estilísticos más determinantes del ultraísmo según Guillermo de Torre son:

"Síntesis [...]. Simultaneísmo [...]. La rima desaparece [...]. Un ritmo unipersonal, vario, mudable, no sometido a pauta [...]. Se suprimen las cadenas de enganches sintácticos [...]. La imagen se identifica con el objeto, le anula, le hace suyo. Y nace la metáfora noviformal [...]. El ultraísmo [...] suprime la puntuación." (Torre, 1974)

Por eso Borges utiliza la metáfora como el procedimiento más importante, junto con imágenes nuevas, chocantes e ilógicas. La rima no existe más, pero los poemas no dejan de ser unidades completas, íntegras - habitualmente se trata de una sola estrofa. Además, es poesía narrativa, o sea, poesía que da la impresión narrativa porque fluye como si fuera hablada. Según Borges:

"El ultraísmo no es quizá otra cosa que la espléndida síntesis de la literatura antigua, que la última piedra redondeando su milenaria fábrica. Esa premisa tan fecunda que considera las palabras no como puentes para las ideas, sino como fines en sí, halla en él su apoteosis." (Borges, 1920)

Sus versos "de la mar al percepto. Del percepto al concepto" (Borges, 1919) simbolizan en cierto modo la aspiración teórica y creativa del ultraísmo. Pero en ningún momento se siente la desintegración del lenguaje como en la poesía de Huidobro. En Borges la gramática funciona bien, su lenguaje es correcto y preciso. Utilizando la terminología de Jakobson (Jakobson, 1958), se puede decir que el eje de combinación funciona bien, sólo hay modificaciones en el eje de selección - crea nuevas e inesperadas combinaciones de palabras, pero nunca pierde el significado, al contrario, su lenguaje es impecable.

La colección de poemas marcadamente ultraístas se encuentra dispersa en las revistas españolas más vanguardistas de la época, Grecia, Ultra, Tableros, Baleares y Cosmópolis. Los poemas que Borges llega a publicar en España entre 1919 y 1922 pueden ser 23. Los poemas Mañana, Catedral, Aldea, Singladura, Distancia, Ultimo rojo sol, Montaña, Sala vacía, Prismas pueden ser incluidas en el corpus ultraísta.

En 1923 publica Fervor de Buenos Aires. El reencuentro con su ciudad natal determina la mayor parte de esos poemas escritos entre 1921 y 1922 que ya se van alejando del "ultraísmo y sus vanidades", aunque algunos de ellos son contemporáneos de los poemas aparecidos en las revistas españolas del ultraísmo. Néstor Ibarra dice que "Borges dejó de ser ultraísta a partir del primer verso ultraísta que escribió" (Milleret, 1970).

La extensión de los poemas en Fervor es bastante desigual, aunque se nota una tendencia a la estrofa única, claro, en verso libre. Borges mismo dice sobre Fervor de Buenos Aires:

Yo me propuse demasiados fines [...] descubrir las metáforas que Lugones ya había descubierto, [...] cantar un Buenos Aires de casas bajas y, hacia el poniente o hacia el sur, de quintas con verjas. (Borges, 1969: 9) 
Se destacan poemas como Las calles:

Las calles de Buenos Aires

ya son mi entraña

$\cdots$

casi indivisibles de habituales

... - y son también la patria - las calles (Borges, 1969: 15);

La Recoleta, donde no canta sólo la belleza de su ciudad natal y de uno de sus símbolos más conocidos, sino también expresa hondos pensamientos sobre la vida y la muerte que no dejan mucho espacio para el optimismo:

sólo la vida existe.

El espacio y el tiempo son normas suyas,

son instrumentos mágicos del alma,

y cuando ésta se apague,

se apagarán con ella el espacio, el tiempo y la muerte (Borges, 1969: 19)

y que están provocados por la ciudad, o más precisamente, por el cementerio La Recoleta:

Estas cosas pensé en la Recoleta,

en el lugar de mi ceniza. (Borges, 1969: 20)

También hay que mencionar El sur y La plaza San Martín, poemas que describen lugares concretos de Buenos Aires (pero sin describir los mismos lugares, sino los sentimientos que provocan y las memorias que evocan), la ciudad percibida como un Barrio reconquistado:

pero un arco bendijo

con colores del perdón la tarde,

$\cdots$

nos echamos a caminar por las calles

como por una recuperada heredad. (Borges, 1969: 51)

Todo el libro trata de los sentimientos provocados por el regreso a su ciudad natal. En Arrabal dice:

El pastito precario,

...

salpicaba las piedras de la calle

y divisé en la hondura

los naipes de colores del poniente

y sentí Buenos Aires. 
Esta ciudad que yo creí mi pasado

es mi porvenir, mi presente;

los años que he vivido en Europa son ilusorios,

yo estaba siempre (y estaré) en Buenos Aires. (Borges, 1969: 71)

Consistente con "las normas" del vanguardismo, las imágenes y las metáforas son muy interesantes. Por ejemplo, en Las calles (Borges, 1969: 15) encontramos "ávidas calles, incómodas de turba y de ajetreo" y "árboles piadosos", en El Sur (Borges, 1969: 23) "mi ignorancia no ha aprendido a nombrar", La plaza San Martín (Borges, 1969: 31) empieza con una imagen inesperada ("En busca de la tarde / fui apurando en vano las calles") y termina con otra aún más inesperada ("Abajo / el puerto anhela latitudes lejanas / y la honda plaza igualadora de almas / se abre como la muerte, como el sueno."). En Un patio (Borges, 1969: 39) leemos que "con la tarde se cansaron dos o tres colores del patio", que "el patio es el declive" y que "serena, la eternidad espera en la encrucijada de estrellas". La sala vacía (Borges, 1969: 55) tiene un tono gracioso, que es resultado de la personificación de las cosas ("Los muebles de caoba perpetúan / entre la indecisión del brocado / su tertulia de siempre") y en Campos atardecidos (Borges, 1969: 139) también encontramos imágenes nocturnas interesantes, como por ejemplo "la soledad poblada como un sueno", "el poniente que no se cicatriza aún le duele la tarde" y "en el dormitorio vacio la noche cerrará los espejos".

Uno de los pocos procedimientos poéticos que Borges y Huidobro tienen en común es la intertextualidad interna. Los dos en varias ocasiones se citan a sí mismos, utilizan los mismos, o casi los mismos versos en varios poemas.

Huidobro, por ejemplo, en el segundo canto de Altazor utiliza el verso "Irías a ser ciega que Dios te dio esas manos?" (Huidobro, 1998: 86, v. 23) que primeramente aparece en 1914 en Las pagodas ocultas, libro dedicado a su esposa. Algo parecido también ocurre en el cuarto canto de Altazor. Semejante, el corpus ultraísta de Borges es una curiosa repetición literal de ciertos versos correspondientes a títulos diversos. Por ejemplo, los tres versos finales de Prismas aparecen literalmente transcritos en Aldea y vuelven a surgir algo transformados en Montaña, donde se repiten los versos 2 y 3 de Prismas. En Ultimo rojo sol y Aldea también. "La luna nueva es una vocecita" aparece también en Campos atardecidos (Borges, 1969: 139).

Sin embargo, ninguno de los dos utiliza la intertextualidad como el procedimiento poético más característico de su poesía, sino, hablando en general, se trata de fenómenos esporádicos. No voy a entrar en el análisis más detallado porque la intertextualidad en las obras de Borges y de Huidobro puede constituir el tema de otro artículo.

Girondo proviene del mismo círculo ultraísta que Borges, lo que explica la utilización de metáforas e imágenes chocantes, pero él lleva su poética 'más allá', por lo menos en cuanto al juego vanguardista con el lenguaje. De las palabras ya existentes crea nuevas palabras y está encantado por tecnicismos que las nuevas tecnologías llevan consigo. Crea imágenes interesantes contraponiendo lo "nuevo" a lo familiar. Frecuentemente utiliza aliteración y asonancia, y reiteración de algunas palabras y así intensifica el efecto audible. 
Hay tres aspectos importantes de la poesía de Girondo: el cosmopolita (es una poesía sin límites geográficos); el visual (se quiere dar una representación visual a las frases y por eso los poemas vienen acompañados por ilustraciones del propio autor); y el fragmentario parecido a la técnica de collage (multiplicidad de los planos que generan un efecto visual).

Entre Los veinte poemas para ser leídos en el tranvía (Girondo, 1922) se destacan algunos: Nocturno (Girondo, 1922) está lleno de imágenes "modernas", como por ejemplo, alambres, postes telefónicos, electricidad, cañería, canillas, y de expresiones nuevas, sorprendentes (trote hueco, intención de los papeles, gritos estrangulados, grillo afóni$c o$, cantar de canillas ...). Es notable la experiencia del mundo exterior a través de los sentidos de tacto ("Frescor de los vidrios al apoyar la frente en la ventana ..."), de oído ("trote hueco de los jamelgos ...", “... aullido de los gatos en celo ...", “... las cañerías tienen gritos estrangulados ...") y de la vista (“... telaraña que los alambres tejen sobre los azotes ...", "... los papeles que se arrastran en los patios vacios ...").

Todas son imágenes de la ciudad, como también los sentimientos que provoca la vida moderna en una ciudad grande. Son sentimientos de soledad, de aislamiento ("... luces trasnochadas que al apagarse nos dejan todavía más solos ...", “... a veces se piensa, al dar vuelta la llave de la electricidad, en el espanto que sentirían las sombras ...” , “... y a veces las cruces de los postes telefónicos, sobre las azoteas, tienen algo de siniestro ..."). Las imágenes de la naturaleza de la poesía anterior están sustituidas por el paisaje urbano ("... telaraña que los alambres tejen ..."). El progreso técnico hace la vida más rápida y aleja al hombre de la naturaleza. De ahí la nostalgia ("... trote hueco de los jamelgos que pasan y nos emocionan sin razón ...", “... súbitamente se comprende que no hay ternura comparable a la de acariciar algo que duerme ..."). El poema concluye con un sentimiento de resignación, de aceptación de la situación del hombre moderno ("... cantar de las canillas mal cerradas! - único grillo que le conviene a la ciudad ...").

Otro nocturno (Girondo, 1922) es otro poema en verso libre que empieza con una de las imágenes más famosas de la vanguardia americana: "La luna, como la esfera luminosa del reloj de un edificio público ...". Esta comparación es una consecuencia lógica de la vida urbana, rápida y consiste en la necesidad ultraísta de crear expresiones chocantes, metáforas y comparaciones inesperadas. Lo mismo pasa con los versos "... faroles enfermos de ictericia ...", "... faroles con gorras de "apache" que fuman un cigarillo en las esquinas", “... cantos humildes y humillados de los mingitoris cansados de cantar ...", pero aquí se nota una personificación, una atribución de las características humanas al paisaje urbano. En todo el poema se puede leer un sentimiento de aislamiento, casi de desesperación ("... por qué a veces sentimos una tristeza parecida a un par de medias tiradas en un rincón ...", "noches en las que nos disimulamos bajo la sombra de los árboles ...", "el único consuelo es la seguridad de que la nuestra cama nos espera ...". La ciudad se ha vuelto en algo siniestro, hostil. El mismo sentimiento será lo que exprese Nicanor Parra años más tarde, en 1948 en Vicios del mundo moderno - "El mundo moderno es una gran cloaca ..." (Parra, 1998: 108, v. 63)

Apunte callejero (Girondo, 1922) es más optimista. El poeta se entusiasma con la vida moderna, urbana. Pero esta vida tan rápida ya empieza a ser un poco exagerada - "Pienso 
en dónde guardaré los quioscos, los faroles, los transeúntes, que se me entran por las pupilas. Me siento tan lleno que tengo miedo de estallar ..."

Para Girondo la poesía es una búsqueda, una liberación de las palabras, una experimentación, una invención de nuevos términos, una asociación de términos incasables, un juego ... Las propiedades combinatorias del lenguaje parecen no tener límites. Utiliza el castellano de Buenos Aires pero inventa palabras (usualmente las agrupa en dos o tres palabras creando una palabra nueva), como por ejemplo hipoteseres (hipótesis de un ser o seres hipotéticos), escleropsiquis, prenoser, grislumbres (de vislumbres cruzados con gris o lumbres cenicientas apagándose), sombracanes, acreencias, neuroyertos (zombis), egohueco, vivisecante, almamasa (sujeto que permanece atado a los medios de desinformación, incluso cuando no lo desinforman), metafisirrata, plenicorrupto, luzlatido ... (Bonal García, 2000)

Algo semejante se nota en la poesía de Vallejo, aunque parece que Vallejo esté más cercano a los procedimientos poéticos y estilísticos de Huidobro. A Vallejo también le entusiasma la modernización, lo que se nota en el uso frecuente de expresiones técnicas y en el uso de números (crea una simbología especial). También el momento visual es muy importante para su poesía - experimenta con signos ortográficos, con mayúsculas y con números, obteniendo de esta manera efectos interesantes. Sus poemas son relativamente cortos, sin rimas, pero dramáticos e impresionantes.

En 1922 publica Trilce - el libro de poesía que rompe completamente con la tradición. Se trata de una poesía absolutamente nueva, de una ruptura radical con la estética anterior. Vallejo se muestra un poeta anti-lírico; aspira a expresar lo inexpresable, no se contenta con el lenguaje que se ve forzado a usar y sólo puede expresar su desesperación en frases que apenas tienen sentido, explorando de este modo los límites del lenguaje. La estructura es una posible estructura castellana, pero carece de sentido:

\author{
Tiempo Tiempo. \\ Mediodía estacando entre relentes. \\ Bomba aburrida del cuartel achica \\ tiempo tiempo tiempo tiempo
}

Era Era. (Vallejo, 1999: 2)

Utiliza un lenguaje 'positivo' - números, fechas, lugares, términos científicos ... ("999 calorías / rumbbb...Trrrapprrr rrach...chaz / serpentínica u del dizcochero"; "Treinta y tres tillones trescientos treinta / y tres calorías" (Vallejo, 1999: 32). Los números son muy importantes porque indican un sentido de armonía y orden que se ha vaciado de significación. De ahí una simbología numérica nueva: cero es nada; uno es símbolo de soledad individual, el ideal imposible de unidad; dos significa una dialéctica sin objeto, la dualidad imposible de la pareja: 
Los novios sean novios en eternidad.

Pues no deis 1 , que resonará al infinito.

Y no deis 0, que callará tanto (Vallejo, 1999: 5);

tres es generación sin sentido; cuatro son las cuatro paredes de la celda:

Oh las cuatro paredes de la celda.

Ah las cuatro paredes albicantes

que sin remedio dan al mismo número. (Vallejo, 1999: 18)

En los 67 poemas numerados sin título la palabra se distorsiona en un intento vano de captar lo inefable. Rechaza la rima y subvierte las convenciones ortográficas, convencido de que un mundo absurdo sólo puede proyectarse con un lenguaje desprendido de la racionalidad:

\author{
Aire, aire! Hielo! \\ Si al menos el calor (- . . . . - - Mejor \\ no digo nada. (Vallejo, 1999: 32)
}

Trilce es un libro vanguardista, pero no sólo por sus rarezas retóricas y fonéticas, o por sus versos en mayúsculas o verticales, sino por la búsqueda de algo que está más allá de la realidad.

\title{
III.
}

Girondo está más cercano a Borges porque los dos son ultraístas y comparten la misma filosofía, y Vallejo está más cercano a Huidobro, pero no lleva la desintegración del lenguaje a tales extremos como Huidobro. Si Huidobro y Borges están en polos opuestos, se puede decir que Girondo y Vallejo se encuentran a medio camino entre ellos.

Como se puede ver, los cuatro poetas vanguardistas rompen las normas antiguas y establecen las nuevas de la poética vanguardista. Lo que sí es fascinante es que su poesía, casi un siglo después de haber sido escrita, sigue siendo vanguardista, nueva y contemporánea, sigue sorprendiéndonos y chocándonos. Lo que quiere decir que los cuatro poetas lograron cumplir con su objetivo principal - ser diferentes.

Borges, después de haber renunciado su breve "equivocación ultraísta", en el prólogo a una edición de Fervor de Buenos Aires, dice que se trataba de un proceso natural:

Como los de 1969, los jóvenes de 1923 eran tímidos. Temerosos de una íntima pobreza, trataban como ahora, de escamotearla bajo inocentes novedades ruidosas. (Borges, 1969: 9)

Pero los vanguardistas fueron más allá de simplemente ser diferentes - permanecieron diferentes. Girondo da las claves del ultraísmo y de su programa ideológico en Martín Fierro, en febrero de 1924, donde dice que 
"todo es nuevo bajo el sol" si todo se mira con unas pupilas actuales y se expresa con un acento contemporáneo. (Girondo, 1924)

Y justamente esta es la razón de la contemporaneidad de la poética vanguardista.

\section{Bibliografia}

Bonal García, F. (2000): "Un poeta de andamios". En: http://meltingpot.fortunecity.com Borges, J. L. (1920): "Al margen de la moderna lírica". En: Grecia, No. 13.

Borges, J. L. (2000): Antología poética 1923 - 1977. Madrid: Alianza Editorial.

Borges, J. L. (1969): Fervor de Buenos Aires. Buenos Aires: Emecé Editores.

Borges, J. L. (1919): "Himno del mar". En: Grecia, No. 37.

Cervera Salinas, V. (1992): La poesía de Jorge Luis Borges: Historia de una eternidad. Universidad de Murcia.

Fernández, T., Millares S., Becerra E. (1995): Historia de la literatura hispanoamericana. Madrid: Editorial Universitas.

Franco, J. (2001): Historia de la literatura hispanoamericana. Barcelona: Editorial Ariel.

Girondo, O. (1924): "Manifiesto". En: Martín Fierro, No. 4.

Girondo, O. (1922): "Veinte poemas para ser leídos en el tranvía". En: www.trincoll.edu.ar

Huidobro, V. (1998): Altazor, Temblor de cielo. Madrid: Cátedra.

Huidobro, V. (1914): Las pagodas ocultas. Santiago: Universitaria.

Jakobson, R. (1958): Linguistica y poética.

Jiménez, J. O. (2000): Antología de la poesía hispanoamericana contemporánea 1814-1987. Madrid: Alianza Editorial.

Milleret, J. (1970): Entrevistas con Jorge Luis Borges. Caracas: Monte Ávila.

Oviedo, J. M. (2001): Historia de la literatura hispanoamericana 3. Postmodernismo, Vanguardia, Regionalismo. Madrid: Alianza Editorial.

Parra, N. (1998): Poemas y antipoemas. Madrid: Cátedra.

Torre, G. de (1974): Historia de las Literaturas de Vanguardia. Madrid: Guadarrama.

Vallejo, C. (1997): España, aparta de mí este cáliz, Poemas humanos. Barcelona: Ediciones 29.

Vallejo, C. (1999): Trilce. Buenos Aires: Editorial Losada. 


\section{ŠTIRJE AVANTGARDNI PESNIKI IN SOČASNOST NJIHOVIH POETIK: HUIDOBRO, VALLEJO, GIRONDO IN BORGES}

Čeprav v Huidobrovi, Vallejovi, Girondovi in Borgesovi poeziji izstopajo najpomembnejše značilnosti avantgardne estetike, so v njej tudi vidne razlike. Huidobra, ki jezik dezintegrira do skrajnosti, in Borgesa, čigar glavni pesniški postopek je metafora, lahko pojmujemo kot nasprotna pola. Girondo in Vallejo sta sredi poti, navdušujejo ju sodobni izrazi, tehnicizmi, znanstveni termini, številke ... Avantgardna poezija je bila nova in šokantna v svojem času, a je še danes zanimiva in preseneča. Skoraj stoletje pozneje je še vedno sodobna. 